\title{
The Quest for Truth of Stephen Hawking
}

\author{
ALFRED DRIESSEN \\ Prof. Emer. University of Twente (The Netherlands) \\ Driessen.Alfred@gmail.com \\ ORCID: 0000-0002-7901-4020
}

\begin{abstract}
With his bestselling publication, A Brief History of Time, Stephen Hawking introduced in 1988 a new genre by connecting modern science with the question of the existence of God. In the posthumous publication Brief Answers to the Big Questions, he continues his quest for the ultimate truth. The current study presents a philosophical analysis of this search in terms of Aristotle's and Aquinas's classical philosophy. Causality is the central concept employed by Hawking. However, in modern scientific and philosophical literature, its meaning is limited to temporal causality compared to the view of classical philosophy. Only the latter one accepts causality from outside space and time, in other words, a reality transcending the material world. In a quote presented in the discussion, Hawking defines himself as an atheist. After a careful reading of his writings, however, doubts arise about his unbelief.
\end{abstract}

Keywords: Hawking; truth; creator; causality; existence of God; Aquinas; Aristotle.

\section{Introduction}

Thirty years ago, Stephen Hawking became a bestselling author with his book A Brief History of Time (Hawking 1988). The book is remarkable, both in the number of copies sold in a non-fiction genre (more than 25 Million) and in the scope of its subject (state-of-the-art cosmology and the existence 
of God). Most revealingly, Carl Sagan wrote in the book's foreword: The word "God" fills the pages. Hawking thus follows a tradition of classical philosophy: one might say, he continues the three millennia-old thread involving Aristotle and medieval authors like Aquinas. These philosophers considered in their metaphysics all reality, including First Mover and First Cause, which they identified with God. They did not do so merely because of their belief. Not at all: they only used human common and less common (proto-scientific) experience of their days and the power of reason. Compared to classical authors, Stephan Hawking has the advantage of leaning on centuries of scientific research instead of on Ancient-Greek or medieval proto-scientific knowledge. In his case, Hawking underpins his arguments with own discoveries, like the quantum-evaporation of black-holes, so-called Hawking radiation (Hawking 1975) or the no-boundary proposal (Hartle and Hawking 1983).

Modern philosophy seems to prefer other approaches, and only a few studies dealt with the metaphysical aspects of A Brief History of Time, see, e.g. (Craig 1990), (Smith 1994) and (Driessen 1995). A bibliographical review of the Cosmological Argument can be found in (Beck 2002). Spitzer discusses Hawking's work in the context of recent developments in cosmology (Spitzer 2010). Hawking himself does not consider his writings as belonging to the realm of philosophy; to the contrary, he believes that philosophy is dead (Hawking and Mlodinow 2010). In his opinion, philosophy should answer "why-questions". In philosophical reflections on the results of modern science, however, they cannot encounter the expected "why-answers". Very recently, (Wilkinson and Hutchings 2020) and (Hutchings and Wilkinson 2020) appreciate the merits of Hawking's work, as it creates new opportunities for a better understanding of God.

A brief history of time may confirm or refute the conviction of its readers regarding the existence of God, but that does not affect his principal merit: elevating the science-based proof of the existence of God to an academic level with millions of interested readers. In his recent posthumous publication, also a bestseller, he writes about the relevance of the question of the existence of God (Hawking 2018, 29): 
People got upset that a scientist should have anything to say on the matter of religion. I have no desire to tell anyone what to believe, but for me asking if God exists is a valid question for science. After all, it is hard to think of a more important, or fundamental, mystery than what, or who, created and controls the universe.

This paper is organized as follows: After the introduction, we present the philosophical framework of $A$ brief history of Time and observe that Hawking refutes the Deistic view on the origin of the universe. Instead, in beautiful lyrics, Hawking shows another road that resembles the $3^{\text {rd }}$ via of Aquinas. After that, as a kind of intermezzo, arguments from classical philosophy and modern science are employed to emphasize that there is causality from outside space and time. In the final discussion, the attention focuses again on the position of Hawking. It reveals a scientist in search of the ultimate truth.

\section{The philosophical framework of $A$ Brief History of Time}

Browsing as a philosopher through this remarkable book, one finds the central concept: causality. With this term already, the misunderstandings and difficulties start. What can be said, for example, of First Cause? Does first mean, first in time, or first in some hierarchical order. Most of the scientists choose first in time in agreement with the view of Hume. This philosopher presents a definition for cause stating (Hume 1748):

a cause to be an object followed by another, and where all the objects similar to the first are followed by objects similar to the second.

In this definition, one does not encounter an explicit reference to time. Nevertheless, when considering a previous observation in the above-cited work, one event follows another, then it appears that follow stands exclusively for succession in time.

The arguments of a previous study (Driessen 1995) include a discussion of the concept of causality within Aristotle's and Aquinas's classical philoso- 
phy. In their work, one finds a broader meaning for cause. They also consider effects obtained by a cause acting in the present time simultaneously and not necessarily in the past. The proofs of God's existence, the five viae of Aquinas, critically depend on this broader meaning.

In this context, it is worthwhile to quote Caleb Cohoe (Cohoe 2013):

Aquinas's conception of causation is much broader than typical contemporary conceptions of causation. On the predominant contemporary conception causation is seen as a one-one relation between events, with the event that is the cause being temporally prior to the event that is the effect. For Aquinas, in contrast, causation covers any sort of ontological dependence between things: it is primarily a vertical relation, not a horizontal one.

Hawking, like most scientists, presents a definition of cause similar to the one given by Hume:

Within the universe, you always explained one event as being caused by some earlier event (Hawking 1988, 7).

Accordingly, his argumentation starts with the observation that if there would be a creator, he should act in the beginning. After that, all is happening according to the laws of nature in a deterministic way. Unforeseen events may happen, but then only by pure chance. These randomly occurring events can be observed in the microscopic world of quantum mechanics and also in biological evolution. According to him, any assumption of divine interference after First Cause's action would be in contradiction to science.

If one analyses the vision of Hawking, a close similarity with Deism becomes apparent. This philosophical attitude emphasizes the intellectual capacity of the human mind and rejects any supernatural revelation. According to Byrne, Deism assumes that natural theology is the true religion; the latter he describes as follows:

Natural theology contains a body of truths about God and his relationship to the world discoverable by the use of unaided human reason and is contrasted with a body of truths - revealed theology - discoverable only by reflection on God's special revelation in history (Byrne 2013,1). 
One should note that 'human reason' in the quote assumes causality in a narrow sense of only temporal causality in agreement with the definitions of Hume and Hawking given above. The notion of Deism includes several different positions regarding God. With Enlightenment, the idea of God converges to a deity with limited capacity acting exclusively in the beginning and with no intervention in the current affairs.

Going back to A Brief History of Time, one observes that a significant part is directed to study the chain of causes from the present to the past. Hawking concludes that it is impossible to assign a unique first point in the history of time. He summarizes his findings:

So long as the universe had a beginning, we could suppose it had a creator. But if the universe is really completely self-contained, having no boundary or edge, it would have neither beginning nor end: it would simple be. What place, then, for a creator? [Hawking 1988, 140-141]

Hawking arrives here at a fundamental conclusion: He starts with the concept of causality involving time separation between cause and effect and uses knowledge exclusively obtained from science. As a result, he puts a question mark for the role of God as the creator. In a universe governed by the rules of physics there is no unique point at the beginning of a series of temporal causes. Consequently, there is no place for God as the creator. Now an important conclusion can be made regarding Deism. Assuming this view on reality, namely accepting exclusively human reasoning and exclusively temporal causality, the existence of God as creator becomes obsolete. In other words, Hawking dismisses the validity of a Deistic approach.

After the publication of a Brief History of Time in 1988, Borde, Guth, and Vilenkin (Borde, Guth and Vilenkin, 2003) presented a study and state:

Our argument shows that null and time like geodesics are, in general, past-incomplete in inflationary models, whether or not energy conditions hold.

The term "past-incomplete" one should read as "requiring a boundary to past time" (Spitzer 2016). The question now arises whether this result 
contradicts Hawking's no-boundary proposal as expressed, e.g., in the above-given quote of Hawking. It is a point of discussion between specialists. Nevertheless, the introduction of imaginary time, see Chapter 8 in (Hawking 1988), seems to be a valid road to avoid the conclusion of the Borde, Guth, and Vilenkin theorem.

Perhaps it is worthwhile to recapitulate the view of (Hawking 1988) in the first 173 of a total of 178 pages. He starts with the definition of causality, which includes in all cases the temporal separation of cause and effect. Accordingly, he is looking for a possible God only in the past. As long as everything evolves according to scientific laws, there is no need for a creator. Only at a boundary or singularity, where the laws of physics break down, the possible creator could act. With the quantum theory of gravity, Hawking now can introduce the possibility that there would be no boundary to space-time. However, all the argumentation is given in a hypothetical sense: if there is exclusively time-related causality, then there is no place for a creator.

Is this the last word science may say regarding the existence of God? Hawking himself does not give up his quest for the ultimate truth. He introduces now in two single sentences an entirely new argument:

Even if there is only one possible unified theory, it is just a set of rules and equations. What is it that breathes fire into the equations and makes a universe for them to describe? [Hawking 1988, 174].

In these two sentences, Hawking makes a distinction between rules or equations, and on the other hand, reality, i.e., the universe. In (Driessen 1995), the four classical aspects of cause were discussed: the material and formal aspects, the efficient and the final cause. In a certain way, the set of rules and equations relates to the formulas, in other words, the formal aspects. In the above quote, Hawking concludes that the formal aspects alone are not sufficient to explain the effect, in this particular case, the universe. Needed is also the efficient cause.

One now could extend the philosophical analysis to the rules and equations. These are expressed in the language of mathematics and provide 
the necessary logical condition for reality. The first condition, namely, for becoming a real object, is to be consistent and free of internal contradiction. As an example, one may mention the squared circle. As this concept is contradictory, it does not appear as an object of reality. On the contrary, according to the laws of logic, what potentially is possible does not necessarily exist actually. The logical possibility is not sufficient to guarantee existence. One could, for example, consider the use of electronic devices in the middle ages. The physics laws then were the same as in the $20^{\text {th }}$ century, but nobody had sufficient knowledge and advanced technology to consider or even fabricate these devices.

Besides logical feasibility, something else seems necessary: an actor who could transform feasibility, i.e., potentially being, in something actually existing. In (Driessen 2018), the discussion focuses on this question. However, the arguments there did not intend to demonstrate the actor's existence with sufficient creative power. Instead, only the possibility of its existence had been considered. After the acceptance of this actor, the challenging relationship between reality and intellectual activity became intelligible.

Aquinas formulated the five viae (five roads) in order to demonstrate the existence of God. In the third one, he presents an argumentation that one finds again in the reasoning of Hawking. For completeness, this road is given here (Davies 2001):

The third way is based on what need not be and what must be, and runs as follows. Some of things we come across can be but need not be, for we find them being generated and destroyed, thus sometimes in being and sometimes not. Now everything cannot be like this, for a thing that need not to be was once not; and if everything need not be, once upon a time there was nothing. But if that were true there would be nothing even now, because something that does not exist can only begin to exist through something that already exists. If nothing was in being nothing could begin to be, and nothing would be in being now, which is clearly false. Not everything then is the sort of thing that need not be; some things must be and these may or may not owe this necessity to something else. But just as we proved that a series of agent [efficient] causes can't go on for ever, so also a series of things which must be and owe this to other things. 
So we are forced to postulate something which of itself must be, owing this to nothing outside itself, but being itself the cause that other things must be. And this is what everyone calls God.

Thomas starts his reasoning and observes that there are things that are beings, they exist, but they exist not necessary: they are contingent. There is nothing against their existence in terms of logic or natural laws, but also nothing regarding their non-existence. See, for example, the occurrence of Dinosaurs during a well-defined period of our earth history. If all beings would be contingent, then one has to consider the situation Aquinas describes as: once upon a time there was nothing. Hawking, on his part, with access to a highly developed formal mathematical framework arrives at a similar position when considering the beings made possible by the laws of nature, but not yet implemented in reality. (Driessen 2018) compares this to the virtual reality generated in a computer game, which is not the actual reality. Hawking writes:

Even if there is only one possible unified theory, it is just a set of rules and equations. (Hawking 1988, 174).

The second argument, Hawking expresses in the form of a question.

What is it that breathes fire into the equations and makes a universe for them to describe?

This question includes a positive statement. The rules and equations do not provide an answer; one has to look outside the realm of mathematics and science. Aquinas, in turn, is forced to postulate something which of itself must be. Looking around where he can find this extraordinary being, Aquinas concludes this is what everyone calls God.

A brief remark comes to the mind. Hawking, who is complaining that philosophy is dead, introduces profound metaphysical statements. Of course, he did not employ the technical language of philosophers but comes up with two beautiful sentences with convincing power. 


\section{Causality from outside space and time}

In the preceding section, two fundamentally different views on causality had been presented: Hume's position with a clear before and after of cause and effect, and the alternative view that cause and effect may be simultaneously, or even from outside time. The power of the arguments of the proof of the existence of God depends mostly on the application of the choice of the concept of causality.

As an example, it is worthwhile to present a quote from Aristotle, Physics VIII, 5 about the unmoved movent (Hardy 2009):

the stick moves the stone and is moved by the hand, which again is moved by the man: in the man, however, we have reached a movent that is not so in virtue of being moved by something else.

Aristotle describes here the chain of movents (or causes) involved in moving a stick. Grammatically one sees that Aristotle uses the present tense. All movents act simultaneously; if one of the movents would stop moving, the stone will be at rest.

What about modern science? Since Einstein and his theory of relativity, one knows that simultaneity and before and after are not uniquely defined. Time is becoming a dependent variable changing by gravity fields and speed. More surprisingly, relativity theory states that time intervals reduce, for massless particles, to zero duration. Fokker, a Dutch physicist who worked for a short time together with Einstein, wrote a textbook on relativity. In the introduction, he writes (Fokker 1965):

Perhaps the deepest enigma brought to light by chronogeometry is the occurrence of zero intervals, connecting events which are located by observers with spatial distance and temporal duration between them. Zero interval means no separation at all, an immediate transmission of momentum and energy, as if there were contiguity [...]. The mathematical formula is quite simple and plain, nevertheless it relates to one of God's secrets and implies His sempiternal ubiquitous presence. 
Penrose expresses the same idea by stating:

The point is that, according to a massless particle, the passage of time is as nothing (Penrose 2010, 146).

Also in quantum mechanics, non-locality and non-temporality are of relevance if one tries to understand the fundamentals of this theory. There are several experiments in quantum mechanics that refer to causality from outside time; for a summary, see a preliminary study (Driessen 2019).

Above already we quoted Hawking:

Even if there is only one possible unified theory, it is just a set of rules and equations. What is it that breathes fire into the equations and makes a universe for them to describe?

The 'rules and equations' include statements about the position and time of particles and events. In relativity, these equations connect time at different places where time-contraction may occur. Consider, for example, a clock on earth and another one far away in a distant galaxy in our expanding universe. It appears that the far-away clock is getting retarded, or even approaches complete rest at high gravity fields nearby a black hole; see, e.g. (Penrose 2010). This relativity of time and simultaneity in modern physics points to a unique property of the actor who can 'breath fire' in this set of rules and' equations. This actor should not be subjected to these 'rules and equations'. The fire should come from outside; the actor should transcend the universe he is 'making', not only regarding place but also regarding time. Therefore, one may safely conclude that Hawking in this quotation implicitly assumes causality from outside space and time.

The concept of creator used in the first part of (Hawking 1988) is according to the Deistic view: if there is a creator, then he is immanent to the space- and time frame that includes the universe. His special status is his relation to the temporal beginning of the universe. William E. Carroll, the Thomas Aquinas Fellow at Oxford, explains that creation is a metaphysical concept and does not just mean change or beginning. He states (Carrol 2010). 
Creation is not primarily some distant event. Rather, it is the ongoing, complete causing of the existence of all that is. At this very moment, were God not causing all that is to exist, there would be nothing at all. Creation concerns the origin of the universe, not its temporal beginning. Indeed, it is important to recognize this distinction between origin and beginning.

The classical proofs of the existence of God by Aristotle, and notably Aquinas, employ the rich meaning of God (or creator), as explained by Carrol. The statements of Hawking deal mostly with the restricted Deistic version of the 'creator'. In this light, the famous quote of Hawking 1988 about the creator contains perhaps more profound truth than initially intended.

So long as the universe had a beginning, we could suppose it had a creator. But if the universe is really completely self-contained, having no boundary or edge, it would have neither beginning nor end: it would simple be. What place, then, for a creator? [Hawking 1988, 140-141]

There is no place for the creator within the space- and time frame, neither for the Deistic creator nor for the God of the classical proof of his existence. The latter transcends the universe entirely he created; he exceeds space and time.

\section{Discussion}

In the preceding sections, Hawking appeared to be a scientist who honestly was in a quest for answers to the big questions. However, could the above argumentation not a little be too speculative about the position of Hawking? Did he consider himself not to be an atheist? In response to a question of Pablo Jauregui he explains in an interview with El Mundo (23 September, 2014):

Before we understand science, it is natural to believe that God created the universe. But now science offers a more convincing explanation. What I meant by 'we would know the mind of God' is, we would know everything that God would know, if there were a God, which there isn't. I'm an atheist. 
There is an interesting description of the funeral by his daughter Lucy. In some detail, she describes the arrival of the hearse at the Great St. Mary's Church in Cambridge (Hawking, L. 2018). Was this a matter of social convention to have a funeral in a Christian church, or was it instead Hawking's positive will? What was his position?

It is worthwhile to quote Leonard Mlodinow, who co-authored several books with Hawking, and who comments about the funeral (Mlodinow 2020, 4):

Some of the eulogies alluded to the irony that Stephen. who did not believe in God, was having his funeral in a church. To me it made sense, for despite Stephen's passionate intellectual belief that the laws of science govern everything that happens in nature, he was a deeply spiritual man. He believed in the human spirit. He believed that all people have an emotional and moral essence that distinguishes us from other animals and defines us as individuals. Believing that our souls are not supernatural, but rather the product of our brains, did not diminish his spirituality. How could it? To Stephen, a man who could neither speak nor move, his spirit was all he had.

There is an interesting observation of the young Ratzinger on fundamental doubts of believers and unbelievers (Ratzinger 1968 and 2004, 44-45):

If on one hand, the believer can perfect his faith only on the ocean of nihilism, temptation and doubt, if he has been assigned the ocean of uncertainty as the only possible site for his faith, on the other hand, the unbeliever is not to be understood undialectically as a mere man without faith. Just as we have already recognized that the believer does not live immune to doubt but is always threatened by the plunge into the void, so now we can discern the entangled nature of human destinies and say that the nonbeliever does not lead a sealed-off, self-sufficient life either. However vigorously he may assert that he is a pure positivist, who has long left behind him supernatural temptations and weaknesses and now accepts only what is immediately certain, he will never be free of the secret uncertainty about whether positivism has the last word. Just as the believer is choked by the salt water of uncertainty, so the unbeliever is troubled by doubts about his unbelief, about the real totality of the world he has made up in his mind to explain as a self-contained whole. 
Reading the last sentence in the Chapter about 'Is there a God?' in Hawking's ultimate book, one gets the impression that Hawking confirms the statement of Ratzinger, that even the unbeliever has doubts about his unbelief:

We have this one life to appreciate the grand design of the universe, and for that I am extremely grateful. (Hawking 2018, 38).

Like in (Hawking 1988), one finds in the bulk of the text arguments why there is no God, and especially no personal God. Then in a single sentence, the unbeliever expresses his doubts of belief and ends up with a statement of faith. He speaks about the grand design. When there is design, then there is a designer, not just blind evolution. Then he concludes with a statement which only real great men can express: for that I am extremely grateful. Living more than 50 years with ALS (amyotrophic lateral sclerosis), bound to a wheelchair, and communicating only by computer, Hawking expresses profound gratitude. Receiving the winning lottery ticket, one is happy but not grateful. Gratefulness always involves a second person. Who is the person whose grand design he appreciates, and to whom he is extremely grateful?

To end up, one should acknowledge the extraordinary effort of Hawking for searching the truth. First, in the field of science and then, more generally, addressing the big questions, including the existence of God. Did he succeed? In any case, he was able to motivate millions of readers to take the big questions seriously.

In this study, like in the work of Hawking, modern science is connected with philosophical questions and argumentations. Hopefully, it demonstrates that classical philosophy based on Aristotle and Aquinas provides valuable input for the quest for the ultimate truth.

\section{References}

Beck, W. David. 2002.”The Cosmological Argument: A Current Bibliographical Appraisal." Philosophia Christi 2 (2): 283-304.

Borde, Arvind, Alan H. Guth, and Alexander Vilenkin. 2003. “Inflationary spacetimes are not past-complete.” Phys. Rev. Letters 90: 151301. 
Byrne, Peter. 2013. Natural Religion and the Nature of Religion, The Legacy of Deism. London, and New York: Routledge.

Cohoe, Caleb. 2013. "Why Thomas Aquinas Rejects Infinite, Essentially Ordered, Causal Series.” Brit. J. for History of Phil. 21: 838-856.

Carrol, William E. 2010. “Stephen Hawking’s Creation Confusion.” Mercatornet, 29-9-2010.

Craig, William Lane. 1990 "What place, then, for a creator?: Hawking on God and Creation.” Brit. J. Phil. Sci. 41: 473-491.

Davies, Brian. 2001. “Aquinas Third Way.” New Blackfriars 82: 450-466.

Driessen, Alfred. 1995. "The Question of the Existence of God in the Book of Stephen Hawking: A brief history of time.” Acta Philosophica: 4, 83-93.

Driessen, Alfred. 2018. “The Universe as a Computer Game.” Scientia et Fides 6: 1-22.

Driessen, Alfred. 2019. “Causality from Outside Time.” Presentation, DOI: 10.13140/ RG.2.2.12414.33602, https://www.researchgate.net/publication/335639016_Causality_from_Outside_Time.

Fokker, Adriaan Daniël. 1965. Time and Space, Weight and Inertia. Oxford: Pergamon Press.

Hardy, R.P., and R.K. Gaye. 2009. “Translation of Aristotle Physics.” The Internet Classics Archive, http://classics.mit.edu//Aristotle/physics.html.

Hartle, James B., and Stephen Hawking. 1983. "Wave Function of the Universe.” Phys. Rev. D. 28: 2960.

Hawking, Stephen. 1975. "Particle creation by black holes.” Commun. Math. Phys. 43: 199-220.

Hawking, Stephen. 1988. A Brief History of Time, from the big bang to black holes. New York: Bantam Books.

Hawking, Stephen, and Leonard Mlodinow. 2010. The grand design. New York: Bantam Books.

Hawking, Stephen. 2018. Brief Answers to the Big Questions. London: John Murray. Hawking, Lucy. 2018. "Afterword” in (Hawking 2018).

Hume, David. 1748. An Enquiry Concerning Human Understanding. https://ebooks. adelaide.edu.au/h/hume/david/h92e/

Hutchings, David, and David Wilkinson. 2020. God, Stephen Hawking and the Multiverse, What Hawking said and why it Matters. London: Society for Promoting Christian Knowledge.

Mlodinow, Leonard. 2020. Stephen Hawking: a memoir of friendship and physics. New York: Pantheon Books.

Penrose, Roger. 2010. Cycles of Time: An Extraordinary New View of the Universe. London: The Boldley Head. 
Ratzinger, Joseph. 2004. Introduction to Christianity. First German edition 1968, second revised edition 2004. San Francisco: Ignatius Press, 44-45.

Smith, Quentin. 1994. "Stephen Hawking’s "Cosmology and Theism.” Analysis 54, 236-243.

Spitzer, Robert J. 2010. New Proofs for the Existence of God: Contributions of Contemporary Physics and Philosophy. Cambridge UK: Wm. B. Erdmans Publishing Co.

Spitzer, Robert J. 2016. "Evidence of God from Contemporary Science \& Philosophy." https://magiscenter.com/wp-content/uploads/2017/07/Contemporary-Evidence-for-God-from-Science-Philosophy.pdf

Wilkinson, David, and David Hutchings. 2020. "How Stephen Hawking's work creates new opportunities for understanding God.” The Tablet 1 February. 